\title{
The Short Physical Performance Battery is a discrimi- native tool for identifying low quality of life in gyne- cological postmenopausal cancer survivor
}

\section{O Short Physical Performance Battery é uma ferramenta discriminativa para identificar baixa qualidade de vida em mulheres na pós-menopausa sobreviventes do câncer ginecológico}

\begin{abstract}
Paulo Ricardo Prado Nunes ${ }^{1}$, Aletéia de Paula Souza ${ }^{1}$, Fernanda Maria Martins ${ }^{1}$, Anselmo Alves Oliveira ${ }^{1}$, Rosekeila Simões Nomelini ${ }^{2}$, Márcia Antoniazi Michelin ${ }^{2}$, Eddie Cândido Murta ${ }^{3}$, Fábio Lera Orsatti ${ }^{1}$
\end{abstract}

\footnotetext{
${ }^{1}$ Universidade Federal do Triângulo Mineiro, Laboratório de Biologia do Exercício - Uberaba. ${ }^{2}$ Universidade Federal do Triângulo Mineiro, Disciplina de Ginecologia e Obstrícia - Uberaba. ${ }^{3}$ Universidade Federal do Triângulo Mineiro, Instituto de Pesquisa em Oncologia - Uberaba.
}

\section{Mailing address}

Anselmo Alves Oliveira

E-mail: anselmogol@yahoo.com.br

Received: May 25, 2018.

Accepted: June 29, 2018.

\section{How to cite}

Nunes PRP, Souza AP, Martins FM, Oliveira AA, Nomelini RS, Michelin MA, et al. The Short Physical Performance Battery is a discriminative tool for identifying low quality of life in gynecological postmenopausal cancer survivor. Acta Fisiatr. 2018;25(1):27-30.

\begin{abstract}
Adverse events due to cancer treatment (changes in weight, reduced muscle capacity and mobility) hinder the quality of life (QoL) of cancer survivors. Nevertheless, the identification of discriminative predictors of QoL in post-menopausal women (PW) survivors of gynecological cancer (PW-SGC) has been ignored. Objective: The purpose of the present study was to examine the role of muscle capacity, mobility and body mass index (BMI) on the deterioration of QoL in PW ( $n=35 ; 62.1 \pm 8.2$ years) and PW-SGC ( $n=51 ; 60.8 \pm 11.4$ years). Methods: The QoL questionnaire (SF-36), anthropometrical evaluation (BMI), hand-held dynamometry (HHD) and short physical performance battery (SPPB) were applied in all volunteers. Results: The participants had overweight, low SF-36 scores and normal HHD, and no significant differences were found between both groups, however the SPPB score was higher in the PW group $(p<0.001)$. Linear regression analyses for QoL indicated the BMI (beta $=-0.27$ ) and the SPPB (beta $=0.57$ ) were the strongest and most significant predictors in PW and PW-SGC, respectively. The area under the curve (AUC) for the SPPB score was $0.74(95 \% \mathrm{Cl}: 0.57-0.87 ; \mathrm{P}=0.015)$ in the PW-SGC group and $0.62(95 \%$ Cl: $0.47-0.75 ; \mathrm{P}=0.181$ ) in PW. Conclusion: The present study showed that the importance of BMI and mobility (SPPB) for QoL differ between PW and PW-SGC. For PW-SGC, the strongest independent predictor of QoL was mobility (SPPB), whereas BMI was the strongest contributor in PW. Moreover, the SPPB test is a discriminative predictor (or assessment tool) for identifying the low quality of life in postmenopausal women survivors of gynecological cancer.
\end{abstract}

Keywords: Aging, Mobility Limitation, Body Mass Index, Muscle Strength Dynamometer, Cancer Survivors

\section{RESUMO}

Efeitos adversos do tratamento (modificações da massa corporal e reduções da capacidade muscular e mobilidade) podem modificar a qualidade de vida (QV) de sobreviventes de câncer. Semelhantemente, a menopausa e o envelhecimento podem promover alterações antropométricas e da função física. Portanto, torna-se necessário o levantamento de ferramentas para predizer, distintamente, a QV em mulheres na pós menopausa (PM) e em mulheres na pós menopausa sobreviventes de câncer ginecológico (PMSCG). Objetivo: Examinar a contribuição da força, mobilidade e do índice de massa corporal (IMC) sobre as alterações da QV em PM ( $n=35$; $62,1 \pm 8,2$ anos) e PMSCG ( $n=51 ; 60,8 \pm 11,4$ anos). Métodos: Aplicou-se questionário de QV (SF36), avaliação antropométrica (IMC), dinamometria de preensão manual (DPM) e short physical performance battery (SPPB). Resultados: Participantes apresentaram sobrepeso, baixo score em SF36 e DPM normal, sem diferenças entre os grupos. O score de SPPB foi maior em PM $(p<0,001)$. Análise de regressão linear de QV, indicou IMC (beta $=-0,27$ ) e o SPPB (beta $=0,57$ ), como os mais fortes preditores em PM e PMSCG, respectivamente. A área sob a curva para o score do SPPB foi 0,74 (95\% Cl: 0,57-0.87; P = 0,015) em PMSCG e 0,62 (95\% Cl: 0,47-0,75; P = 0,181) em PM. Conclusão: $O$ presente estudo demonstrou que para PMSCG o principal preditor da QV foi a mobilidade (SPPB), enquanto o IMC foi o mais forte contribuidor em PM. Portanto, o SPPB é um teste específico para identificar reduções na QV pacientes sobreviventes de câncer ginecológico.

Palavras-chave: Envelhecimento, Limitação da Mobilidade, Índice de Massa Corporal, Dinamômetro de Força Muscular, Sobreviventes de Câncer 
Nunes PRP, Souza AP, Martins FM, Oliveira AA, Nomelini RS, Michelin MA, et al. The Short Physical Performance Battery is a discriminative tool for identifying low quality of life in gynecological postmenopausal cancer survivor

\section{INTRODUCTION}

Although the most common treatments (surgery, radiation therapy, and systemic therapy) in cancer have documented survival advantage, the implications for quality of life may not be negligible. ${ }^{1-3}$ Depending on the location, extent, and duration these treatments may cause various adverse events (e.g. pain, fatigue, low functional capacity) in cancer survivors. ${ }^{1-5}$ These adverse events can become persistent for years, impacting on quality of life (QoL) of cancer survivors..$^{2-6}$

Excess weight body weight (body mass index; BMI), low muscle strength and low mobility (changing body positions, carrying or moving objects, or walking and moving) alterations have been shown to be critical determinants of independent functioning, a central tenet of QoL in cancer survivors. ${ }^{2,3,7}$ However, those alterations in $\mathrm{BMI}$, muscle strength and mobility have also been observed in postmenopausal (PW) and older women who did not have cancer, ${ }^{8}$ making difficult our understanding of a relationship between adverse effects of cancer treatment and risk for low QoL in PW gynecological cancer survivors (PWGCS).

Little attention has been given to identification of discriminative predictors to a low quality of life in PWGCS. To the best of our knowledge, no study has examined the specific contribution of muscle strength, mobility, and $\mathrm{BMI}$ to deterioration of QoL in PW and PWGCS separately. As the identification of discriminative predictors to QoL is critical for advancing our understanding of a relationship between adverse events of cancer treatment and risk for a low quality of life, the lack of this information delineates the importance of examining strength, mobility and obesity in PW and PWGCS separately. Moreover, early identification of discriminative predictors to a low QoL may be a key issue in preventing low QoL 2-6,9 in PWGCS. Thus, an appropriate discriminative predictor for identifying people at risk for a low QoL progression in the near future is important, particularly in routine clinical care.

\section{OBJETIVE}

The purpose of the present study was to examine the contribution of strength, mobility, and BMI to deterioration of QoL in PW and PWGCS separately. We hypothesized that PWGCS would have different predictors for QoL when compared to PW.

\section{METHODS}

This cross-sectional study was concluded with 86 women, attended between January and November of 2015 in Breast and Gynecologic Clinic at the Hospital of the Federal University of Triângulo Mineiro, Brazil. All volunteers included were PW aged 50 or older, characterized by spontaneous amenorrhea for at least 12 months, radical hysterectomy surgery or endocrine therapy (anastrozole and tamoxifen). The inclusion criteria consisted of: No hormone replacement therapy or phytoestrogens and no several physical limitations (wheelchair, canes or any similar device). The initial evaluation consisted of an interview about behavioral habits, history of illnesses and medicine intake. After the QoL questionnaire (SF-36) was applied. Finally, all the volunteers were submitted to an anthropometrical evaluation and physical performance tests: hand-held dynamometry (HHD) and the short physical performance battery (SPPB). All selected women agreed with the terms of the study and signed the free and informed consent approved by the Research Ethics Committee of the Federal University of Triângulo Mineiro, Brazil ( $n$. 1090676).

\section{Anamnesis}

Preliminarily, all volunteers were submitted to anamnesis to detect age, labor situation, indicators of health and history of past and present illnesses and medicinal intake. It was identified 35 PWCGS (breast cancer, 54.9\%; uterine cervical cancer, $29.4 \%$; endometrial cancer, $5.9 \%$; ovarian cancer, $5.9 \%$ and vaginal cancer, 3.9\%). Medicine intake included lipidlowering drugs (statins and fibrates), bloodpressure-lowering drugs (beta blockers, calcium blocker channel, diuretics and ACE blockers) glucose-lowering drugs (insulin and metformin), anti-inflammatory drugs (AINES), anti-depressive drugs and estrogen blockers (tamoxifen).

\section{Quality of life questionaire SF-36}

The SF-36 consisted of a multidimensional questionnaire consisting of 36 items encompassed in eight scales or components: functional capacity, physical aspects, pain, general health, vitality, social functioning, emotional aspects and mental health. For each component, there is a final score of zero to 100 , where zero is the worst general health status and 100 the best state of health, the sum of all components compromises of zero to $800 .^{10}$

\section{Anthropometric and body composi- tion assessments}

Body weight and height were measured with a digital scale (Lider, Brazil) and a stadiometer fixed to the scale, respectively. The BMI was classified according to the system used by the World Health Organization.

\section{Physical performance tests}

All physical tests were performed in the following order: HHD and SPPB.The HHD test was measured with a manual dynamometer (Jamar", Brazil) to detect global muscle strength in the right hand. Three measures were taken and the mean was calculated as the valid measure. ${ }^{11}$

The SPPB consisted of three tests to detect mobility and the tests were performed in the following order: balance test, four-meters walk test (FMWT) and five-time-sit-to-stand test (FTSST). Each test score varied to zero to four points, and the SPPB scorer varied to zero to 12 points (sum of the scores of the three tests). ${ }^{12}$

The balance test consisted of three positions: Side-by-Side Stand, Semi-Tandem Stand, and Tandem Stand. The score was based on the time hold (10 seconds) in each position.

The FMWT test was evaluated by the time walked in a distance of four meters which the volunteer auto selected the velocity. Two measures were taken and the minor time was considered as the valid measure.

The FTSST test was evaluated by the time spent in five maximum velocity squats in a chair with the arms folded across the chest. The technique consisted of full sit and stand position and the volunteer started in the sit position.

\section{Statistical analysis}

Data distribution was determined using the D'Agostino-Person test. The data are presented as mean and standard deviation (SD). T-test was used to compare groups (PW and PWGCS). Multiple regression analysis was used to associate variables independents (BMI, HHD and SPPB score) with variable dependent (QoL score). Receiver operating characteristic (ROC) curves and area under the curve (AUC) analysis were used to assess the accuracy of SPPB in determining QoL. 
The lowest quartile of QoL was coded in both groups to determine the AUC. The significant level was set at $p<0.05$.

\section{RESULTS} of groups were interpreted and statistically compared (Table 1). The age values were within the normal range for PW, and there was no difference between groups. In mean values, the participants showed overweight (i.e BMI > $24.9 \mathrm{~kg} / \mathrm{m} 2$ ), low SF36 and normal HHD (i.e. $>20 \mathrm{~kg}$ ), with no differences between groups. The participants showed normal SPPB score (i.e. score $>6$ ); however, there was a difference between groups and the SPPB score was higher in the PW group.

Condition-specific linear regression analyses, performed to examine the relative importance of predictor variables for QoL in PWGCS and PW, indicated that the strongest predictors of QoL differed between conditions (Table 2). In PW, BMI was the significant predictor after adjustment for age. Each standard deviation increase in BMI was associated with a mean QoL (standard deviation) decrease of $27 \%$. In PWGCS, SPPB was the significant predictor of QoL; each standard deviation increase in SPPB was associated with a mean QoL increase of $57 \%$.

Measures of diagnostic accuracy (ROC curves and AUC) of the SPPB and QoL in PWGCS and PW are shown in Figure $1 \mathrm{~A}$ and $\mathrm{B}$,
At first, the baseline clinical characteristics

respectively. The AUC for the SPPB score was 0.74 (95\% confidence interval $[\mathrm{Cl}]$ : 0.57-0.87; $\mathrm{P}=0.015)$ in PWCGS. In PW, the AUC for the SPPB score was 0.62 (95\% confidence interval [Cl]: 0.47-0.75; $\mathrm{P}=0.181$ ).

\section{DISCUSSION}

The major findings from this study suggest that the relative importance of status of weight (BMI) and mobility (SPPB) for QoL differ between PW and PWGCS. For PWGCS, the strongest independent predictor of QoL was SPPB, whereas BMI was the strongest contributor in PW. Thus, the SPPB test is a discriminative predictor (or tool) for identifying a low quality of life in postmenopausal women gynecological cancer survivor. This study contributes to the literature by presenting novel findings regarding the specific contributors that impact QoL in PWGCS and PW.

To the best of our knowledge, this is the first study that examined the importance of BMI, muscle strength, and mobility to QoL in condition-specific analyses of PW and PWGCS. We observed that the SPPB test was the strongest independent predictor of QoL, whereas $\mathrm{BMI}$ was the strongest contributor in PW. Moreover, we found that the SPPB test was suitable for identifying PWGCS with low QoL, but was not for PW.

Because limitations in mobility are often the first signs of further functional decline,

Table 1. Participant characteristics

\begin{tabular}{lcccc}
\hline & PWGCS $(n=35)$ & PW $(n=51)$ & Delta & $P^{*}$ \\
\hline Age, years & $60.8 \pm 11.4$ & $62.1 \pm 8.2$ & -1.3 & 0.537 \\
\hline BMl, $\mathrm{kg} / \mathrm{m} 2$ & $29.6 \pm 5.9$ & $29.1 \pm 5.9$ & 0.5 & 0.719 \\
FMWT, $\mathrm{m} / \mathrm{s}$ & $0.9 \pm 0.2$ & $1.1 \pm 0.2$ & -0.2 & 0.000 \\
FTSST, s & $14.9 \pm 3.4$ & $11.4 \pm 2.6$ & 3.5 & 0.000 \\
SPPB, total score & $8.5 \pm 2.0$ & $11.0 \pm 1.3$ & -2.5 & 0.000 \\
HHD, kg & $23.0 \pm 6.1$ & $23.8 \pm 5.9$ & -0.7 & 0.567 \\
\hline SF36, total score & $427.7 \pm 80.8$ & $404.9 \pm 86.4$ & 22.8 & 0.213 \\
\hline
\end{tabular}

Post-menopausal women (PW), PW gynecological cancer survivors (PWGCS), body mass index (BMI), Five-time-sit-to-stand test (FTSST), four-meters walk test (FMWT), Short Physical Performance Battery (SPPB), hand-held dynamometry (HHD), Differences between groups (Delta). $\mathrm{kg}=\mathrm{kilo}$ grams, $\mathrm{m}=$ meters, $\mathrm{s}=$ seconds, ${ }^{*}=\mathrm{t}$ test of student (independent)

Table 2. Independent predictors of SF36 from condition-specific linear regression analyses

\begin{tabular}{lcccccc}
\hline & \multicolumn{3}{c}{ PWGCS (N=35) } & \multicolumn{2}{c}{$P W(\mathrm{~N}=51)$} \\
\hline & Beta & SE & $P$ & Beta & SE & P \\
BMl, $\mathrm{kg} / \mathrm{m}^{2}$ & -0.13 & 0.17 & 0.468 & -0.27 & 0.13 & 0.049 \\
$\begin{array}{l}\text { SPPB, total } \\
\text { SCore }\end{array}$ & 0.57 & 0.21 & 0.013 & 0.20 & 0.14 & 0.154 \\
HHD, $\mathrm{kg}$ & 0.28 & 0.17 & 0.119 & -0.04 & 0.15 & 0.798 \\
\hline
\end{tabular}

Post-menopausal women (PW), PW gynecological cancer survivors (PWGCS), standard error (SE), short physical performance battery (SPPB), handheld dynamometry (HHD), body mass index (BMI).PWGCS and PW groups were adjusted to age.
$9,13,14$ the lower SPPB values and the negative association between SPPB and QoL observed solely in PWGCS suggest that development of limitations in mobility is a premature event in the course of PWGCS, leading to low QoL., ${ }^{2,3}$ As the common treatments in cancer have been reported to reduce muscle mass in cancer patients, ${ }^{2,3,7,15} \mathrm{PW}$ with gynecological cancer may not recovery muscle after treatments. ${ }^{16-22}$ A sexually dimorphic effect of aging on skeletal muscle protein synthesis has been shown by Smith et al. ${ }^{17,19,23}$ Hence, it has been suggested that PW are less responsive to physiological muscle growth stimuli (nutrition and physical activity) than older men, suggesting that older women exhibit poor muscle recovery following disuse-related muscle loss. ${ }^{20-22}$ Thus, our results are important because the identifying of a discriminative predictor to poor mobility has been advocated as a key issue in preventing disability 9 and consequently low QoL in PWGCS.

Unlike the results observed in SPPB test, the results from analyses of the HHD showed that this was not a relevant factor in the discrimination of QoL in PWGCS. These results suggest that lower extremity strength (SPPB) might be more relevant than upper extremity strength (HHD) to QoL in PWGCS. It has been shown that lower body extremity strength is important for functional activities in older adult, ${ }^{24}$ an important predictor of QoL in cancer survivors. ${ }^{2,3,7}$ The SPPB test had the highest value for predicting low QoL because the cluster of tests in SPPB (standing balance tests, Five-Times-Sit-to-Stand Test, and 4-meter gait speed) is to assess the lower body extremity physical function, which reflects the potential for daily life activities such as standing up from a sitting position and walking or carrying a bag. Moreover, although HHD strength is easy to apply and has low cost, the use of HHD as a predictor of lower body extremity strength has been unjustified by Samuel et al. ${ }^{24}$

Despite our findings that the SPPB showed good clinical validity, limitations should be noted. This study was restricted to a cross-sectional strategies and small sample; therefore, the discriminative ability of the SPPB may not be generalizable to different settings. In this context, future studies should consider these associations prospectively, and a large sample should be included. However, discriminative predictors can be well estimated from controlled studies. None of the controlled studies has been designated to determine discriminative predictors for identifying a low quality of life 


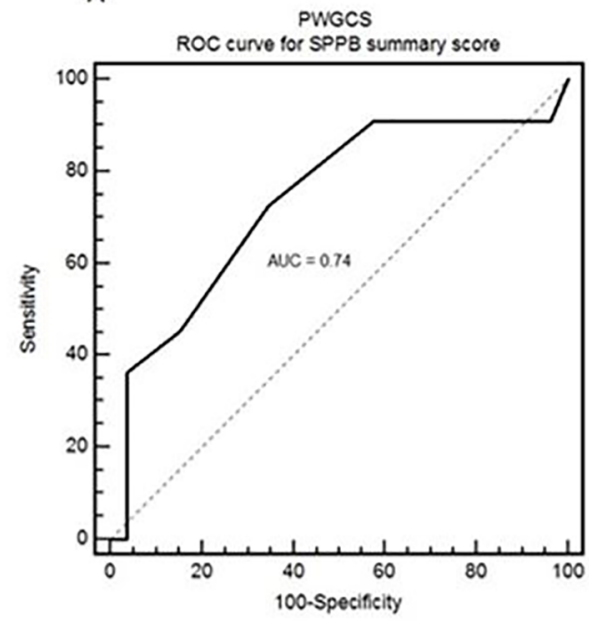

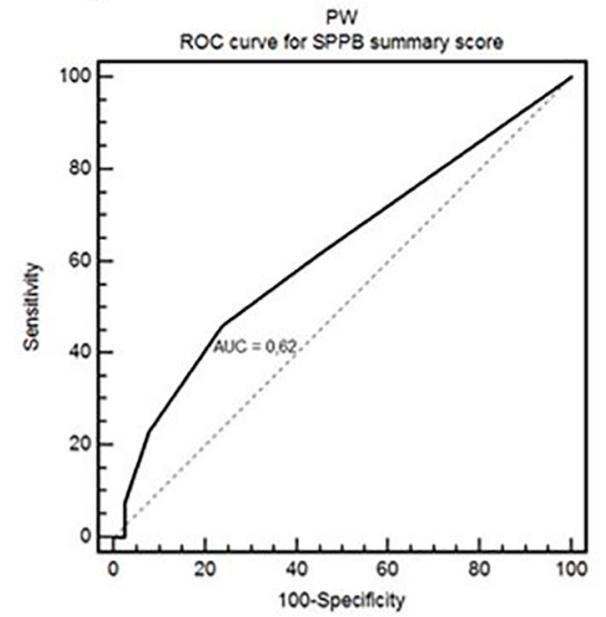

Lines show the specificity and sensitivity for the SPPB in determining QoL for PWGCS (A) and PW (B). Abbreviations: area under the curve (AUC), receiver operating characteristic (ROC), quality of life (QoL), Post-menopausal women (PW), PW gynecological cancer survivors (PWGCS), Short Physical Performance Battery (SPPB).

Figure 1. ROC curves for SPPB scores.

in postmenopausal women gynecological cancer survivor, making our study important, particularly in routine clinical care.

\section{CONCLUSION}

To sum up, our study showed that the relative importance of $\mathrm{BMI}$ and physical capacity for QoL differs between PW and PWGCS. For PWGCS, the strongest independent predictor of QoL was mobility (SPPB), whereas weight status (BMI) was the strongest contributor in PW. Moreover, the SPPB test is a discriminative predictor (or tool) for identifying a low quality of life in postmenopausal women gynecological cancer survivor.

\section{ACKNOWLEDGEMENTS}

This investigation was supported by Fundação de Amparo à Pesquisa do estado de Minas Gerais - FAPEMIG. We thank Patrícia Nacamura for assisting us with the subjects.

\section{REFERENCES}

1. Stone P, Hardy J, Broadley K, Tookman AJ, Kurowska A, $A^{\prime}$ Hern $R$. Fatigue in advanced cancer: a prospective controlled cross-sectional study. $\mathrm{Br} \mathrm{J}$ Cancer. 1999;79(9-10):1479-86. DOI: https://doi. org/10.1038/sj.bjc.6690236

2. Courneya KS. Exercise in cancer survivors: an overview of research. Med Sci Sports Exerc. 2003;35(11):1846-52. DOI: https://doi. org/10.1249/01.MSS.0000093622.41587.B6
3. Schmitz KH, Courneya KS, Matthews C, DemarkWahnefried W, Galvao DA, Pinto BM, et al. American College of Sports Medicine roundtable on exercise guidelines for cancer survivors. Medicine and science in sports and exercise. 2010;42(7):1409-26. DOI: https://doi.org/10.1249/MSS.0b013e3181e0c112

4. Martins da Silva RC, Rezende LF. Assessment of impact of late postoperative physical functional disabilities on quality of life in breast cancer survivors. Tumori. 2014;100(1):87-90. DOI: https:// doi.org/10.1177/1430.15821

5. Rietman JS, Geertzen JH, Hoekstra HJ, Baas P, Dolsma $W V$, de Vries J, et al. Long term treatment related upper limb morbidity and quality of life after sentinel lymph node biopsy for stage I or II breast cancer. Eur J Surg Oncol. 2006;32(2):148-52. DOI: https://doi. org/10.1016/j.ejso.2005.11.008

6. Goedendorp MM, Gielissen MF, Verhagen CA, Bleijenberg G. Development of fatigue in cancer survivors: a prospective follow-up study from diagnosis into the year after treatment. J Pain Symptom Manage. 2013 Feb;45(2):213-22. DOI: https://doi.org/10.1016/j.jpainsymman.2012.02.009

7. Chlebowski RT, Aiello E, McTiernan A. Weight loss in breast cancer patient management. J Clin Oncol. 2002;20(4):1128-43. DOI: https://doi.org/10.1200/ JCO.2002.20.4.1128

8. Brady AO, Straight CR. Muscle capacity and physical function in older women: What are the impacts of resistance training? J Sport Health Sci. 2014;3(3):179-88.

9. Studenski S, Perera S, Wallace D, Chandler JM, Duncan PW, Rooney E, et al. Physical performance measures in the clinical setting. J Am Geriatr Soc. 2003;51(3):314-22. DOI: https://doi.org/10.1046/ j.1532-5415.2003.51104.x

10. Lyons RA, Perry HM, Littlepage BN. Evidence for the validity of the Short-form 36 Questionnaire (SF-36) in an elderly population. Age Ageing. 1994;23(3):182-4. DOI: https://doi.org/10.1093/ageing/23.3.182

11. Bohannon RW, Peolsson A, Massy-Westropp N, Desrosiers J, Bear-Lehman J. Reference values for adult grip strength measured with a Jamar dynamometer: a descriptive meta-analysis. Physiotherapy. 2006;92(1):11-5. DOI: https://doi. org/10.1016/j.physio.2005.05.003
12. Guralnik JM, Simonsick EM, Ferrucci L, Glynn RJ, Berkman LF, Blazer DG, et al. A short physical performance battery assessing lower extremity function: association with self-reported disability and prediction of mortality and nursing home admission. J Gerontol. 1994;49(2):M85-94. DOI: https://doi. org/10.1093/geronj/49.2.M85

13. Eisner MD, Iribarren C, Blanc PD, Yelin EH, Ackerson L, Byl N, et al. Development of disability in chronic obstructive pulmonary disease: beyond lung function. Thorax. 2011;66(2):108-14. DOI: https:// doi.org/10.1136/thx.2010.137661

14. Guralnik JM, Ferrucci L, Simonsick EM, Salive ME, Wallace RB. Lower-extremity function in persons over the age of 70 years as a predictor of subsequent disability. N Engl J Med. 1995;332(9):556-61. DOI: https://doi.org/10.1056/NEJM199503023320902

15. Dimeo FC. Effects of exercise on cancer-related fatigue. Cancer. 2001;92(6 Suppl):1689-93. DOI: https://doi.org/10.1002/1097$0142(20010915) 92: 6+<1689::$ A I D CNCR1498>3.0.CO;2-H

16. Holm L, Olesen JL, Matsumoto K, Doi T, Mizuno $\mathrm{M}$, Alsted TJ, et al. Protein-containing nutrient supplementation following strength training enhances the effect on muscle mass, strength, and bone formation in postmenopausal women. J Appl Physiol (1985). 2008;105(1):274-81. DOI: https://doi. org/10.1152/japplphysiol.00935.2007

17. Smith GI, Atherton P, Villareal DT, Frimel TN, Rankin $D$, Rennie MJ, et al. Differences in muscle protein synthesis and anabolic signaling in the postabsorptive state and in response to food in 65-80 year old men and women. PLoS One. 2008;3(3):e1875. DOI: https://doi.org/10.1371/journal.pone.0001875

18. Holm L, Esmarck B, Suetta C, Matsumoto K, Doi T, Mizuno $M$, et al. Postexercise nutrient intake enhances leg protein balance in early postmenopausal women. J Gerontol A Biol Sci Med Sci. 2005;60(9):1212-8. DOI: https://doi.org/10.1093/gerona/60.9.1212

19. Smith GI, Villareal DT, Sinacore DR, Shah $K$ Mittendorfer B. Muscle protein synthesis response to exercise training in obese, older men and women. Med Sci Sports Exerc. 2012;44(7):1259-66. DOI: https://doi.org/10.1249/MSS.0b013e3182496a41

20. Machida S, Booth FW. Regrowth of skeletal muscle atrophied from inactivity. Med Sci Sports Exerc. 2004;36(1):52-9. DOI: https://doi.org/10.1249/01. MSS.0000106175.24978.84

21. Suetta C, Hvid LG, Justesen L, Christensen U, Neergaard $\mathrm{K}$, Simonsen $\mathrm{L}$, et al. Effects of aging on human skeletal muscle after immobilization and retraining. J Appl Physiol (1985). 2009;107(4):1172-80. DOI: https://doi.org/10.1152/japplphysiol.00290.2009

22. Suetta $C$, Frandsen $U$, Mackey AL, Jensen L, Hvid LG, Bayer ML, et al. Ageing is associated with diminished muscle re-growth and myogenic precursor cell expansion early after immobilityinduced atrophy in human skeletal muscle. J Physiol. 2013;591(15):3789-804. DOI: https://doi. org/10.1113/jphysiol.2013.257121

23. Smith GI, Reeds DN, Hall AM, Chambers KT, Finck BN, Mittendorfer B. Sexually dimorphic effect of aging on skeletal muscle protein synthesis. Biol Sex Differ. 2012;3(1):11. DOI: https://doi.org/10.1186/20426410-3-11

24. Samuel D, Rowe P. An investigation of the association between grip strength and hip and knee joint moments in older adults. Arch Gerontol Geriatr. 2012;54(2):357-60. DOI: https://doi.org/10.1016/j. archger.2011.03.009 